\title{
Áureo carmesim: conflitos e disputas pela exploração de ouro em Serra Pelada*
}

\author{
Crimson Gold: Conflicts and Disputes \\ Over Gold Exploration in Serra Pelada
}

\section{Áureo carmesí: conflictos y disputas por la exploración de oro en Serra Pelada}

\author{
Tallyta Suenny Araujo da Silva** \\ (D) http://orcid.org/0000-0001-5430-6230 \\ Universidade Federal do Pará, Brasil \\ tallytasuenny@gmail.com
}

Resumo: A região de Serra Pelada e arredores foi palco de diversos conflitos relacionados com a garimpagem de ouro. Durante o funcionamento de Serra Pelada, memórias desses conflitos ficaram registradas em reportagens, fotografias e nos relatos e lembranças de quem vivenciou esses momentos. $\mathrm{O}$ presente trabalho objetiva, refletir sobre os conflitos sociais, políticos e econômicos que ocorreram na vila de Serra Pelada em torno do funcionamento do garimpo e que resultaram em um episódico violento que ficou conhecido como o Massacre de São Bonifácio. Para isso, foram levantadas fontes escritas e reportagens televisivas. Analisando as relações de poder, verifica-se que os garimpeiros de Serra Pelada ganharam poder e força de negociação graças ao

* Pesquisa financiada pelo programa de bolsas da Capes.

** Mestre em Antropologia, ênfase em Arqueologia (PPGAn/ufmg). Doutoranda em Antropologia, ênfase em Arqueologia pelo Programa de Pós-Graduação em Antropologia da Universidade Federal do Pará.

cómo citAR: Araujo da Silva, T. S. (2021). Áureo carmesim: conflitos e disputas pela exploração de ouro em Serra Pelada. Secuencia (109), e1756. DoI: https://doi.org/10.18234/secuencia.v0i109.1756

c) Esta obra está protegida bajo una Licencia Creative Commons Atribución-NoComercial 4.0 Internacional. 
seu quantitativo, mas o governo sempre buscou meios de manter os garimpeiros sobre controle, sendo o Massacre de São Bonifácio um ato de violência extremado em reação à ameaça contra sua autoridade.

Palavras-chave: Serra Pelada; garimpagem; conflitos; guerra da Ponte.

Abstract: The Serra Pelada region and its surroundings were the scene of several conflicts related to gold mining. During the Serra Pelada operation, the memories of these clashes were recorded in reports, photographs and the stories and recollections of those who lived through those moments. This article seeks to reflect on the social, political, and economic struggles that took place in the town of Serra Pelada over the mining operation, which erupted into a violent episode that became known as the São Bonifácio Massacre. To this end, it examines written sources and television reports. Analyzing the power relations, it would seem that although the Serra Pelada miners gained strength and bargaining power through their numbers, the government has always sought ways to keep the miners under control, the São Bonifácio Massacre being an act of extreme violence in response to the threat to its authority.

Keywords: Serra Pelada; gold mining; conflicts; guerra da Ponte.

Resumen: La región de Serra Pelada y sus alrededores fue escenario de varios conflictos relacionados con la minería de oro. Durante la operación de Serra Pelada, los recuerdos de estos conflictos quedaron registrados en reportajes, fotografías y en los relatos y memorias de quienes vivieron estos momentos. El presente trabajo tiene como objetivo reflexionar sobre los conflictos sociales, políticos y económicos que ocurrieron en el pueblo de Serra Pelada en torno al funcionamiento de la minería y que resultaron en un episodio violento que se conoció como la Masacre de São Bonifácio. Para ello, se revisaron fuentes escritas y reportajes televisivos. Analizando las relaciones de poder, parece que los mineros de Serra Pelada ganaron poder y fuerza negociadora gracias a su cantidad, pero el gobierno siempre ha buscado formas de mantener a los mineros bajo control, siendo la Masacre de São Bonifácio un acto de extrema violencia en reacción a la amenaza contra su autoridad. 
Palabras clave: Serra Pelada; minería de oro; conflictos; guerra de Ponte.

Recibido: 10 de junio de 2019 Aceptado: 19 de febrero de 2020

Publicado: 11 de febrero de 2021

\title{
SEGURANÇA E TECNOLOGIA: A MELHOR FORMA PARA EXPLORAR O OURO DE SERRA PELADA
}

\begin{abstract}
A des descoberta de ouro, no final de 1979, na fazenda de Genésio em questão de meses, atraiu vários garimpeiros para a região. $O$ garimpo ganhou destaque a tal ponto que o governo militar decidiu interferir na área a fim de controlar a exploração de ouro e a evasão do minério. A exploração desse recurso e seu controle pelo Estado brasileiro influenciaram não só o domínio sobre a exploração de um recurso e de um espaço, mas, consequentemente, teve repercussão no modo de vida dos indivíduos que se instalaram no garimpo de Serra Pelada, e das cidades que foram surgindo ao redor. Serra Pelada, assim, adquiriu o caráter de um garimpo atípico, considerando as intervenções externas as quais foi submetido (Salomão, 1984).

Segundo Salomão (1984), a midiação em torno de Serra Pelada garantiu que o modo de produção de um grupo social, que frequentemente esteve a margem da sociedade, se tornasse notícia nacional. Serra Pelada virou tema de documentários, reportagens televisivas e jornalísticas, filmes e ensaios fotográficos, durante o seu funcionamento, e mesmo posteriormente. São várias as imagens retratando os barrancos escavados, as pessoas transportando sacos cheios de terra para verificar a presença de ouro, os barracões onde os garimpeiros habitavam, etc.

A exploração intensa do ouro em um espaço relativamente reduzido foi criando uma cratera, que se tornou um dos motivos do discurso de órgãos governamentais, que defendiam a necessidade da interrupção da garimpagem manual, visto que a mesma não apresentava os meios necessários para retirar o ouro em grandes profundidades de forma segura. $\mathrm{O}$ embate entre fechamento e reabertura de Serra Pelada para a garimpagem manual durou anos, embasando diversos protestos e apelos dos garimpeiros para que Serra Pelada continuasse na mão desses trabalhadores. Um desses protestos em específico sofreu uma resposta violenta das forças policiais a mando do governador Hé-
\end{abstract}


lio Gueiros, o conflito ficou conhecido como Guerra de São Bonifácio, ou o Massacre da Ponte (Ferreira, 2019).

Este artigo objetiva revisitar as notícias presentes em periódicos do Brasil que retratam o impasse sobre a melhor forma de exploração do ouro de Serra Pelada. A questão tinha implicações, que estavam para além de qual seria a melhor e a mais segura forma de tecnologia para a retirada do minério, envolvendo questões econômicas, tanto no que diz respeito ao lucro com o ouro, quanto ao que fazer com a mão de obra dos garimpeiros retirados de Serra Pelada; juntamente com implicações políticas e relações de poder (Figueiredo, 1984). Nesse sentido, a Guerra de São Bonifácio, em 1987, foi um exemplo extremado de embate desses elementos, visto que os interesses políticos, econômicos e a autoridade do governo entrou em conflito com o poder adquirido pelos garimpeiros. A resposta do conflito de poderes entre $o$ governo paraense e os garimpeiros foi a violência, como forma instrumental destrutiva de um desses poderes.

\section{PODER DOS GARIMPEIROS, PODER SOBRE OS GARIMPEIROS: EXPLORAÇÃO DO OURO E RELAÇÕES ENTRE ESTADO E GARIMPEIROS}

Arendt (1994) conceitua que o poder reside no grupo, no consentimento da maioria, é assim a habilidade humana de agir em conjunto, que, portanto, existe enquanto o grupo se mantém unido. Em contrapartida, a violência é um instrumento, ao qual se recorre quando o poder que um indivíduo ou instituição detinha é contestado. Arendt afirma ainda que a violência pode destruir o poder, dessa forma se o poder é concedido a alguém ou a alguma instituição pela maioria, mas em determinado momento essa maioria, ou parte dela contesta a autoridade da pessoa escolhida, em resposta, a pessoa ou instituição eleita usa da violência para manter seu poder e destruir o poder de quem lhe contesta.

Utilizando, portanto, a conceituação de Arendt sobre violência e poder, no contexto do garimpo em Serra Pelada deparamo-nos com uma situação na qual o garimpo e os garimpeiros ganharam atenção do Brasil e do governo, adquirindo poder em decorrência do número expressivo de pessoas que foram à Serra Pelada garimpar, e também pelas repercussões políticas surgidas dessa massiva concentração. Em contrapartida, o governo brasileiro 
tomou medidas para o controle desses garimpeiros, para manter seu poder e a soberania nacional no controle do ouro.

Segundo o Jornal do Brasil, de 21 de abril de 1980, a descoberta de ouro se tornou o assunto mais falado em Marabá e trouxe grande movimentação para a cidade. Como fatores motivadores para a grande migração para os garimpos estão a seca no Nordeste, as enchentes na Amazônia e a recessão econômica vivida no Brasil ${ }^{1}$ (Kotscho 1984). Para Salomão (1984), de uma forma geral, a explosão garimpeira estaria relacionada com as políticas de ocupação acelerada para a Amazônia. A importância de Serra Pelada foi tanta que, a quantidade de ouro extraída chegou a corresponder a 52\% do volume nacional de ouro durante a década de 1980 (Monteiro, Coelho, Cota y Barbosa, 2010).

A fim de controlar o fluxo de pessoas na área e a exploração de ouro, visto que ambos poderiam representar uma ameaça à segurança nacional, em abril de 1980, o major Sebastião Curió, juntamente com oito homens da Polícia Federal e do Exército, chegaram a Serra Pelada para instalar um regime de controle governamental sobre o garimpo (Kotscho, 1984; Cleary 1992; Monteiro, Coelho, Cota y Barbosa, 2010). O major Sebastião Rodrigues de Moura, conhecido como Major Curió, já havia realizado operações nas proximidades de Carajás, em anos anteriores, sendo o responsável pelo trabalho de inteligência militar para combater a Guerrilha do Araguaia, ocorrida entre 1967 e 1974.

A posse de armas individuais foi proibida com a intervenção militar (Mathis, Brito, Brüseke, 1997; Cleary, 1992). Além do controle de possíveis ações violentas pela apreensão das armas, a presença da força policial e da Caixa Econômica foram medidas para controlar a compra ilegal do ouro. $\mathrm{O}$ exemplar do Diário da Tarde de 9 de julho de 1980 confirma o papel fiscal e controlador da Caixa Econômica Federal na evasão do ouro recorrente em garimpos. ${ }^{2} \mathrm{O}$ uso "racional" e "objetivo" dos recursos compõem um discurso de longa data na ocupação da Amazônia, e que serviu de pauta para várias práticas intervencionistas governamentais através de projetos e instituições (Almeida, 2008). Dentro dessa lógica, o controle governamental do garimpo

${ }^{1}$ Para uma análise da migração dos trabalhadores rurais do Nordeste para a Amazônia, ver, por exemplo, Araújo (2015). Para a relação dos moradores de Marabá com as enchentes, ver, por exemplo Almeida (2011). Para as consequências da situação econômica no Brasil com as políticas adotadas para a garimpagem, ver, por exemplo Mathis (1997) e Salomão (1984).

2 "Ouro poderá pagar a dívida externa", Diário da Tarde, ano 81 n. 23244, Curitiba, 9 de julho de 1980, p. 4. 
era, provavelmente, defendido como racional, e, consequentemente, benéfico para o país e para os próprios garimpeiros.

Junto com a instalação de um banco público, o controle do ouro foi realizado também por outros métodos. Em 4 de maio de 1980, o Jornal do Brasil noticiou que a Polícia Federal interditou o aeroporto de Marabá, a fim de impedir a decolagem de aviões com destino à Serra Pelada que tinham como passageiros compradores de ouro não autorizados que já vinham agindo na negociação clandestina do minério.

A entrada de novos garimpeiros também ficou proibida. Foi implantado o registro dos garimpeiros que já se localizavam na Serra Pelada, para impedir que novas pessoas entrassem na área aumentando ainda mais o contingente de pessoas, que estimasse ter sido entre 80000 a 100 000, em 1983 (Cleary, 1992).

Não obstante, como proposto por Weber (1999) em sua teoria social, poder, dominação e disciplina têm significados distintos, e as imposições de poder por parte do governo para garantir o domínio sobre a exploração em Serra Pelada não implicaram em uma obediência automática dos garimpeiros. Dessa forma, as pessoas ainda arriscavam a sorte, sendo às vezes descobertas e expulsas do garimpo.

Observa-se, assim, que o regime militar pretendeu de diferentes formas exercer o controle e instalar a disciplina no garimpo, seja econômico, pela administração da comercialização do ouro, seja social, ao fiscalizar as pessoas que entravam no garimpo, o consumo de álcool, e, inclusive, o "patriotismo", por meio do hasteamento da bandeira do Brasil e reprodução do hino nacional (Cleary 1992; Kotscho, 1984). O controle exercido no garimpo levou Kotscho (1984) a comparar o contexto de Serra Pelada com o de um campo de concentração, já que a circulação pela área necessitava de autorização e revista rigorosa.

Nesse sentido, observa-se uma aproximação do contexto de Serra Pelada com a perspectiva de Foucault (1987) sobre a disciplina. Com isso, no garimpo há a disciplina com a distribuição dos indivíduos no espaço, tanto o espaço mais amplo que representava a área do garimpo, quanto dos espaços de menor escala, as catas, espaço designado, sobre o controle governamental, para cada dono de barranco e seus trabalhadores garimparem. Têm-se assim a "cerca" e "quadriculamento" (Foucault, 1987, pp. 122-123), um local heterogêneo e fechado em si, no caso do garimpo. Fechado em si, enquanto espaço 
para exploração do ouro, visto que os garimpeiros circulavam para fora do garimpo.

Dessa forma, mais do que um espaço disciplinar, Serra Pelada parece ser um espaço de segurança (Foucault, 2008), no qual tentou-se maximizar a coleta de ouro, que deveria ir preferencialmente para os cofres governamentais, e minimizar os riscos e inconvenientes que o adensamento populacional na área do garimpo poderia trazer para as redondezas de Carajás, sem contudo atingir um ponto de perfeição, uma "cidade disciplinar". Um espaço de segurança que se tentava disciplinar.

O garimpo de Serra Pelada era uma "instituição total" (Goffman, 1987) nos dias de semana, quando os diferentes aspectos da vida social estavam concentrados na área interna da vila e se limitava o contato social com o mundo exterior. Nos domingos, após o meio dia, os garimpeiros saiam da vila e frequentavam bares e boates das redondezas, como os que existiam no $\mathrm{Km} 30$ da rodovia, vilarejo que posteriormente se tornou a cidade de Curionópolis, ou para cidades mais longes como Marabá, conforme as riquezas alcançadas em cada bamburro (Kostcho, 1984).

O controle dos corpos no garimpo de Serra Pelada se verificava principalmente na tentativa de evitar conflitos internos, e externos, no que diz respeito às consequências que a retirada de milhares de pessoas do garimpo poderia trazer para os municípios da redondeza, em questões sociais e econômicos. especialmente para a questão da terra (Cleary, 1992; Figueiredo 1984; Mathis, 1997). Os agentes do Sistema Nacional de Informação acreditavam que o garimpo era uma forma útil de proteger as fazendas contra a mão-de-obra invasora desocupada (Kotscho 1984, p. 14), e a concentração de garimpeiros também representava um grande eleitorado potencial (Cleary 1992, p. 165).

Apesar de intervir nesses corpos para maximizar as técnicas de retirada do ouro, havia um discurso que considerava o garimpo manual inferior à extração mecanizada. A visão pejorativa para com a atividade do garimpo já vinha de época mais antiga. O Código de Mineração instituído pelo Decreto Lei núm. 227, de 28 de fevereiro de $1967,{ }^{3}$ em seu sexto capítulo declara a garimpagem a partir do trabalho individual e pelo uso de instrumentos rudimenta-

${ }^{3}$ Decreto-Lei núm. 227, de 28 de fevereiro de 1967. Código de Mineração. Recuperado de http://www2.camara.leg.br/legin/fed/declei/1960-1969/decreto-lei-227-28-fevereiro-1967-376017-publicacaooriginal-1-pe.html 
res que, que podem ser aparelhos manuais ou as máquinas simples e de fácil transporte. Dessa forma, juridicamente, a garimpagem foi considerada como uma técnica rudimentar de mineração, e, em alguns discursos, é possível verificar a extensão desse caráter rudimentar a quem trabalhava dessa forma.

Barbosa (1981) compara a imagem construída sobre a figura do garimpeiro do século XVIII com a do século $\mathrm{xx}$, enquanto no primeiro caso, $\mathrm{O}$ garimpeiro era tido como um herói nacional, desbravador, civilizador e povoador das fronteiras da nação; o garimpeiro dos tempos atuais, entretanto, se opõe ao novo modelo nacional assentado na modernidade. Com isso, na modernidade, ao garimpeiro foram imputados atributos negativos, quase como estivessem na "contramão da história", visto que a história é interpretada como se fosse uma linha de progresso e desenvolvimento. Dessa forma para o garimpeiro do século $\mathrm{xx}$ em diante, enfatiza-se principalmente seu caráter atrasado, e destruidor. Destruição do meio ambiente, pelo mercúrio, e das sociedades indígenas, por adentrarem nas terras dos povos indígenas para poder garimpar.

Tecnicamente e culturalmente inaptos, além de sujeitos à manipulação de ideias subversivas, os garimpeiros necessitavam de apoio e orientações para trabalhar de forma eficiente. Tal perspectiva perpassa pela tradição colonialista e paternalista que perdura no Brasil de diferentes formas (ver, por exemplo, Freyre, 2003; Schwarcz, 1993). Ideias evolucionistas e racistas frequentemente estão no fundamento das ações colonialistas e paternalistas, visto que um povo ou um grupo é tido como inferior e, consequentemente, precisa que seres mais instruídos, mais evoluídos, para alcançar os patamares mais próximos da civilização.

Santos (2010) designa de "sociologia das ausências" os discursos criados pelas epistemologias dominantes que produziram a não existência daqueles com epistemologias distintas por meio de sua desqualificação, tentando assim invisibilizar o "outro", classificando-o como não inteligível ou indesejável. Há uma racionalidade cultural que estabelece como padrão, como correto, apenas a sua concepção de mundo. Santos definiu cinco formas de produção de ausências: o ignorante, o atrasado, o inferior, o local ou particular e o improdutivo ou estéril.

$\mathrm{Na}$ controvérsia entre garimpagem e mineração, o governo militar estava diante de um impasse. Entre os fatores que incentivavam o fechamento de Serra Pelada estavam a pressão do setor de mineração e seus discursos sobre a ineficácia e falta de segurança da garimpagem manual frente à exploração 
mecanizada, juntamente com a violação do direito de lavra concedida à Companhia Vale do Rio Doce, desde 1974 (Cleary, 1992). Entre os fatores favoráveis à manutenção econômica havia a crise econômica na qual o país encontrava-se, o aumento da cotação do ouro nos mercados internacionais, e os perigos latentes que o fechamento do garimpo poderia trazer, seja para a questão agrária, historicamente problemática nessa região do Pará, seja para o projeto de mineração Carajás, tão próximo ao garimpo de Serra Pelada. A balança acabou pesando para o lado da permanência dos garimpeiros de Serra Pelada, peso que acabou pressionando o governo a manter o garimpo aberto por mais tempo do que planejado.

Serra Pelada se tornou a esperança para sanar a dívida externa. Nesse sentido, entretanto, o discurso sobre os garimpeiros não é sempre homogêneo, cambiando entre o anonimato e o reconhecimento dos garimpeiros na extração aurífera. O próprio major Curió, em seus discursos matinais na Serra Pelada, reforçava entre os garimpeiros a importância patriótica do trabalho daqueles cidadãos para sanar a dívida externa do Brasil, ${ }^{4}$ prometendo ainda aos garimpeiros intervir em Brasília para garantir mais vantagens para aquela gente. Essa posição de Curió a favor da população mais pobre, segundo o jornal Movimento, em sua edição de 10 a 16 de novembro de 1980, começou em Marabá e arredores, após a repressão da Guerrilha do Araguaia.

\section{GARIMPAGEM OU MINERAÇÃO?: A TRAJETÓRIA DE DISPUTAS SOBRE A MANUTENÇÃO DO GARIMPO}

Ainda em 1980, a Companhia Vale do Rio Doce já pressionava o Ministério de Minas e Energia a se pronunciar a respeito de que a intervenção em Serra Pelada tinha caráter provisório e que em breve a área seria entregue à Companhia (Cleary, 1992, p. 168). O fim do garimpo manual estava previsto para o ano de 1981, consequentemente, como mencionado pelo jornal de Tocantins de dezembro de 1980, a preocupação dos garimpeiros já existia desde o ano anterior.

Para reforçar a necessidade da lavra mecanizada, utilizou-se como argumento o perigo representado pelos desabamentos dos barrancos. O jornal

4 "Nós falamos com o venerado e temido homem da selva. O homem deste governo. O major Curió”, Movimento, ano 0, núm. 266, Rio de Janeiro, 4 a 10 de agosto de 1980, pp. 12-13. 
Alto Madeira de 10 de outubro de 1981, menciona que o acidente ocorrido na primeira semana de outubro reforçou a medida existente já há algum tempo sobre a desativação do garimpo. ${ }^{5}$ Ainda nesta edição do Alto Madeira, o Diretor-Geral do Departamento Nacional de Produção Mineral (DNPM), Yvan Barreto, menciona que no ano de 1981, a produção de ouro estava estimada para onze toneladas, apesar da extração desse ouro estar sofrendo riscos devido aos vários desabamentos que vinham ocorrendo, consequência do que Yvan designou "buraqueira que foi feita sem nenhuma coordenação" pelos garimpeiros. ${ }^{6}$

Não obstante, a tão esperada transferência para a lavra mecanizada por uns também não se concretizou em 1982. No final de 1981, em reportagem do jornal Diário da Tarde de 14 de dezembro, Curió já anunciara que a lavra mecanizada seria adiada para $1983,{ }^{7}$ pois a extração manual ainda era considerada viável em 1982, apesar dos vários empecilhos ocasionados por desmoronamentos e pelas escavações terem atingido o lençol freático, pois o governo estava realizando o rebaixamento das paredes do garimpo e a drenagem da água que infiltrava. Para 1982, a produção oficial do ouro foi de $6820 \mathrm{~kg}$, aproximadamente $260 \%$ a mais do que no ano anterior (Mathis, Brito y Brüseke, 1997, p. 135).

Afora a rentável produção de ouro e de ser um meio para conter os conflitos sociais, Serra Pelada se tornou um local também interessante para a obtenção de votos. Para conseguir a maior quantidade de votos possíveis, o sistema de controle de acesso ao garimpo foi suavizado, facilitando a entrada e permanência dos "furões" no garimpo, o que iria, consequentemente, aumentar a possibilidade de votos (Cleary, 1992; Kostcho, 1984). Devido a essa estratégia, em 1982, o contingente de garimpeiros em Serra Pelada chegava a 45000 homens.

Apesar das vantagens eleitorais, como em Serra Pelada sempre estiveram em jogo interesses diversos, as pressões para a adoção da técnica de exploração mecanizada continuaram. O Diário da Tarde de 21 de janeiro de 1983, expõe que, segundo o ministro Cesar Cals, O Ministério das Minas e Energias

5 “Garimpo da Serra Pelada perto de desativação", Alto Madeira, ano LXIV núm. 13858, Porto Velho, 10 de outubro de 1981, p. 2.

6 "Falta verba para descobrir o ouro", Alto Madeira, ano LXIV núm. 13858, Porto Velho, 10 de outubro de 1981, p. 6.

7 "Serra Pelada será aberta ao garimpeiro", Diário da Tarde, ano 81, núm. 23779, Curitiba, 14 de dezembro de 1981, p. 5. 
já havia estudado a retirada dos garimpeiros, que ocorreria apenas nas áreas onde a extração manual fosse insegura. ${ }^{8}$

Se para a teoria hobbesiana, a segurança do povo era um objetivo do Estado (Hobbes, 1983), e que atualmente considera-se como uma das funções fundamentais do Estado (Weber, 1999), o discurso de segurança também ser compreendido como uma maneira de instituir o funcionamento de estruturas da lei e da disciplina (Focault, 2008). O discurso de segurança para o garimpo era, portanto, uma forma renovada para pôr novamente em ação o poder governamental de controle sobre a extração do ouro de Serra Pelada.

O Diário da Tarde de 24 de setembro de 1983 informa que quatro áreas do garimpo, "Malvinha", "Serrinha", "Segurança da Planada" e "Planada" tinham sido interditadas, o que resultou em aproximadamente a proibição de extração em aproximadamente $60 \%$ da área do garimpo. ${ }^{9}$ A reportagem comenta que as fortes chuvas que caiam na região alagaram o fundo da cava, dificultando ainda mais a tentativa de secar a área com as bombas de sucção já utilizadas para combater a água que vinha dos lençóis freáticos (ver mapa 1).

Esse seria o último ano da extração manual, pois, novamente, o prazo para a saída dos garimpeiros foi estabelecido: 15 de novembro (Kostcho, 1984, p. 20). Alegava-se que os garimpeiros de Serra Pelada seriam transferidos para os garimpos de Cumarú, no rio Xingu, e do rio Tapajós, como informado pelo Jornal do Brasil de 21 de abril de $1983 .{ }^{10}$ Entretanto, os anos de 1983 e 1984 representaram um acirramento no embate da permanência ou interrupção da garimpagem manual, nesse período, os garimpeiros se articularam de diferentes maneiras para permanecer na Serra Pelada.

Uma das estratégias para manter a extração manual foi o discurso sobre a dívida externa. Se em um primeiro momento, o discurso patriótico de que o ouro de Serra Pelada poderia salvar o Brasil da dívida externa foi proferido pelos governantes para os garimpeiros, nesse novo impasse entre extração mineral e mecanizada, os garimpeiros que iriam utilizar esse argumento para tentar permanecer em Serra Pelada, à fim de ajudarem a sanar as dívidas da nação. O Diário de Pernambuco em 11 de setembro de 1983 informa que os

8 “Retirada”, Diário da Tarde, ano 83, núm. 24299, Curitiba, p. 5, 21 de janeiro de 1983.

9 "Interdição", Diário da Tarde, ano 84, núm. 24507, Curitiba, 24 de setembro de 1983, p. 6.

10 "Garimpo de ouro vai para Xingu", Jornal do Brasil, ano xcIII, núm. 13, Rio de Janeiro, 21 de abril de 1983, p. 18. 
Mapa 1. Organização da área do garimpo e divisão da cava de Serra Pelada
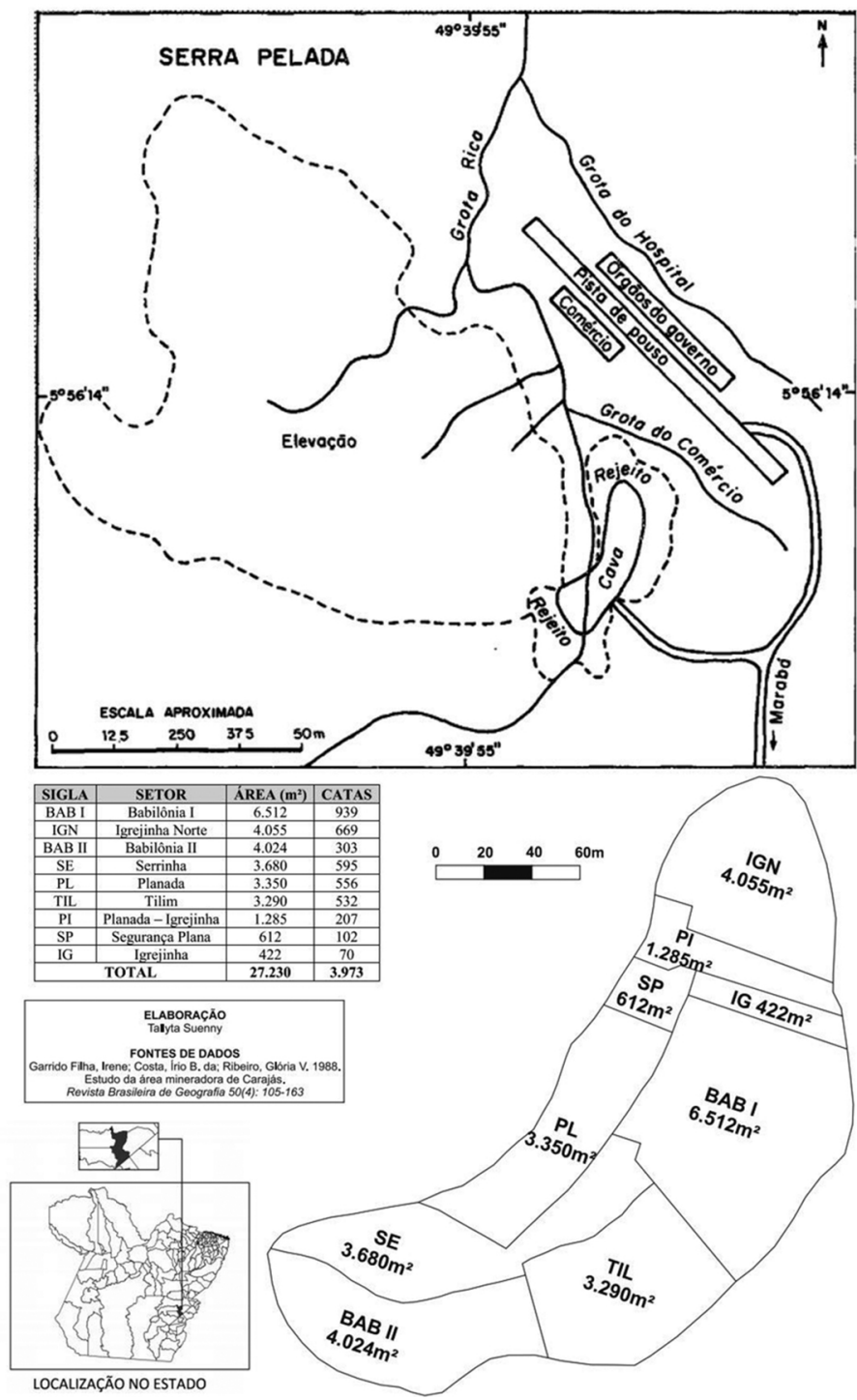
garimpeiros prometeram doar $10 \%$ que seria extraído caso eles pudessem continuar a trabalhar na cava. ${ }^{11}$

Os garimpeiros procuraram se mobilizar de diferentes formas, ainda que em certos momentos sofressem repressão governamental. O Jornal do Brasil de 18 de abril de 1983 anuncia que garimpeiros de Marabá foram proibidos pela Polícia Federal de se reunirem, entretanto, a mobilização ocorria em diferentes lugares a fim de impedir o fechamento do garimpo. ${ }^{12}$ Quando o deputado Curió lançou seu projeto para a permanência do garimpo, segundo matéria do Jornal do Brasil de 1 de outubro de 1983, uma caravana de 100 ônibus que conduziam 3000 garimpeiros se dirigiu à Brasília para apoiar o deputado. ${ }^{13}$ A caravana foi organizada pelo Sindicado dos Garimpeiros, que antes tinha pouca atuação, mas em decorrência da iminência do fechamento de Serra Pelada iniciou medidas para prevenir tal acontecimento. Os garimpeiros apelaram à imprensa, aos sindicatos de metalúrgicos de todo o Brasil, aos políticos e a entidades como a Ordem dos Advogados do Brasil, e em pouco tempo, o sindicato dos garimpeiros apresentava 3465 associados (Kostcho, 1984, pp. 71-73).

Além do acompanhamento ao projeto do deputado Curió, como tentativa de pressão política, os garimpeiros também recorreram ao meio jurídico, entrando com uma liminar em Marabá, visando manter o garimpo (Kostcho, 1984, p. 57). Corriam notícias ainda de uma possível resistência armada, com boatos de que a Polícia Federal teria apreendido metralhadoras e revólveres em Serra Pelada (Kostcho, 1984, pp. 22, 57). No Diário de Pernambuco de 11 de setembro de 1983, os garimpeiros lembraram que o Ministério das Minas e Energia havia concedido 6000 concessões de lavra, e que, se fosse necessário entrariam com um mandado de segurança para a manutenção da posse das áreas concedidas para lavra.

A reação dos que desejavam o fim do garimpo foi em alguns momentos mais enérgica do que os já mencionados discursos de inferioridade da extração manual em comparação à mecanizada, ou do discurso sobre a preocupação com a segurança e vida dos garimpeiros. O jornal Luta Democrática de

11 "Garimpeiros prometem doar ouro para reduzir dívida externa do País", Diário de Pernambuco, ano 158, núm. 251, Recife, 11 de setembro de 1983, p. 16.

12 "Garimpeiros ameaçados de perder Serra Pelada levam tensão a Marabá", Jornal do Brasil, ano xcIII, núm. 10, Rio de Janeiro, 18 de abril de 1983, p. 12.

13 "Garimpeiros irão a Brasília defender lavra em S. Pelada", Jornal do Brasil, ano xcIII, núm. 176, Rio de Janeiro, 1 de outubro de 1983, p. 4. 
19 de outubro de 1983 relata que Curió teria denunciado a violência infligida contra os garimpeiros, ${ }^{14}$ quando policiais armados com metralhadoras, a mando do Departamento Nacional de Mineração, teriam espancado, na sexta-feira do dia 14 de outubro, alguns garimpeiros em Serra Pelada e danificado seus equipamentos.

A cisão de interesses era crescente, pois os locais beneficiados pelo garimpo tinham receios sobre as consequências que a abrupta interrupção causaria. Antes da anunciada data de fechamento do garimpo, Figueiredo, em 30 de setembro de 1983, decidiu retirar a coordenação do garimpo das mãos do Serviço Nacional de Informação (SNI) e transferi-lo para o DNPM, que seria, assim, o responsável pela retirada dos garimpeiros (Mathis, 1995). A expulsão dos garimpeiros, entretanto, não ocorreu, Figueiredo em novembro cedeu às pressões dos grupos que defendiam a manutenção da garimpagem.

Com a vitória da lavra manual, o DNPM declarou que também sairia da coordenação do garimpo de Serra Pelada, mas ao órgão ainda estava incumbida a decisão de autorizar as obras de rebaixamento e medidas de segurança na cava, o que limitou as conquistas que os garimpeiros aparentemente tinham adquirido. Valendo-se desse poder, o DNPM atrasou seu veredito, causando apreensão entre os garimpeiros nos primeiros meses de $1984 .{ }^{15}$

Pela matéria do jornal Luta Democrática de 21 de fevereiro de 1984 é possível inferir o possível motivo do atraso na liberação das obras na cava.${ }^{16} \mathrm{O}$ Departamento mantinha sua posição contrária a manutenção da garimpagem por ser uma medida contrária ao direito de lavra concedido primeiramente a Companhia Vale do Rio Doce. Na reportagem do Luta Democrática, o Incra manifestou seu apoio ao DNPM ao afirmar que não iria apoiar a constituição da cooperativa de garimpeiros.

A resistência do setor mineral e seus aliados novamente enfrenta a união dos garimpeiros que em maio de 1984 se reuniram, em número aproximado de 20 000, nas cidades de Imperatriz e de Marabá em Assembleia Geral, momento em que foi decidido o estabelecimento de um prazo para o ministro César Cals assinasse a portaria que reabriria a garimpagem, caso

14 “Ouro de Serra Pelada foi vendido, diz Curió”, Luta Democrática, ano xxx, núm. 8637, Rio de Janeiro, 19 de outubro de 1983, p. 3.

15 "Serra Pelada", Última Hora, ano xxxiII, núm. 11245, Rio de Janeiro, 2 de abril de 1984, p. 2.

${ }_{16}$ "Incra não aprovará cooperativa de garimpeiros de Serra Pelada", Luta Democrática, ano xxxi, núm. 8724, Rio de Janeiro, 21 de fevereiro de 1984, p. 3. 
contrário, estariam dispostos a tomar decisões mais drásticas, como a invasão da Serra Pelada e o fechamento de rodovias importantes na região do Pará. ${ }^{17}$

O prazo estabelecido foi de 13 de maio de $1984,{ }^{18}$ e na véspera do término desse prazo, a tensão chegou tal ponto que os garimpeiros em Serra Pelada ameaçaram derrubar a tiros um helicóptero da Companhia Vale do Rio Doce (CVRD), enquanto em Marabá, soldados da 23ª Brigada da Infantaria do Exército tomaram diversas precauções contra possíveis atos dos garimpeiros, como a ocupação da ponte sobre o rio Itacaiúnas e a realização de manobras ao longo da rodovia Transamazônica. ${ }^{19}$

O conflito não foi deflagrado no dia 13 , visto que as obras de rebaixamento foram finalmente autorizadas por Figueiredo. Não obstante, como a liberação para a garimpagem não se concretizou, na primeira quinzena de junho os garimpeiros voltaram a protestar. O jornal Correio de Notícias de 8 de junho de 1984 apresentou matéria que anunciava a interdição de estradas, depredação de prédios, destruição parcial de uma ponte e o incendeio de carros ocorridos nos estados do Pará e do Maranhão. ${ }^{20}$ Além desses atos, os garimpeiros em Parauapebas sequestraram um major da Polícia Militar paraense que tentava negociar com os manifestantes. ${ }^{21}$

A mesma matéria noticiou o quase embate físico entre a Polícia Militar e os garimpeiros, que tentavam destruir o aeroporto de Carajás e outras instalações da Companhia Vale do Rio Doce. Mesmo diante desses eventos, Figueiredo declarou que decisões não seriam tomadas sob pressão, visto que a demora na sanção era para garantir a segurança dos garimpeiros. ${ }^{22}$

O ano de 1985 foi igualmente problemático para a garimpagem. Conflitos internos sugiram com denúncias de irregularidades na administração da Cooperativa dos Garimpeiros de Serra Pelada (Cooagar), de proibição, com

17 “Revolta domina garimpeiros", Última Hora, ano xxxiII, núm. 11 276, Rio de Janeiro, 8 de maio de 1984, p. 3.

18 "Tensão aumenta em Serra Pelada", Última Hora, ano xxxıII, núm. 11 278, Rio de Janeiro, 10 de maio de 1984, p. 8 .

19 "Garimpeiros fazem festa na Serra", Última Hora, ano xxxıII, núm. 11306, Rio de Janeiro, 12 de maio de 1984, p. 3.

20 "Serra Pelada: zona do garimpo em guerra", Correio de Notícias, ano IV, núm. 886, Curitiba, 8 de junho de 1984, p. 3.

21 "Garimpo: cresce a tensão. Major capturado", Correio de Notícias, ano IV, núm. 887, Curitiba, 9 de junho de 1984, p. 6.

22 "Exército pode intervir em Serra Pelada", Correio de Notícias, ano IV, núm. 887, Curitiba, 9 de junho de 1984, p. 7. 
uso de força, do trabalho em algumas áreas da cava, de aprisionamento de garimpeiros, de grilagem de barrancos e de contrabando de ouro. ${ }^{23}$ A dívida contraída pela Coogar aumentava paulatinamente, e, a semelhança com a dívida externa do Brasil, não importava quanto ouro fosse retirado do garimpo, a quantia não era suficiente para o endividamento contraído para as obras de rebaixamento. $^{24}$

O acirramento em 1986 das relações entre garimpeiros e a polícia teve repercussões que irromperam no ano seguinte, na repressão policial que foi designada como Guerra de São Bonifácio. A desavença teve como fator desencadeador o assassinato de um garimpeiro por um policial militar, acontecimento que revoltou os garimpeiros de Serra Pelada, que em revide lincharam o policial, destruindo e ateando fogo no alojamento da PM, na Delegacia de Serra Pelada ${ }^{25}$ e da Coogar. ${ }^{26}$

Segundo matéria do Diário do Pará de 14 de outubro de $1986,{ }^{27}$ o desentendimento começou quando um dos trabalhadores diaristas atingiu com uma pedra o soldado da PM, que em represália atirou com seu fuzil. O conflito resultou na morte de dois garimpeiros e mais oito feridos, ${ }^{28}$ juntamente com a expulsão de oito policiais civis e 25 soldados da Polícia Militar. ${ }^{29} \mathrm{~A}$ morte do garimpeiro teria sido apenas o estopim de fatores acumulados, pois os garimpeiros há muito tempo já estavam contrariados com o roubo de cascalho, a ser processado para verificar presença de ouro, além de outras arbitra-

23 "Garimpeiros de Serra Pelada denunciam a Cooperativa. Garimpeiros estão contra os dirigentes e solicitam sindicâncias", Diário do Pará, ano III, núm. 680, Belém, 22 de janeiro de 1985 , p. 6.

${ }_{24}$ "Ouro não está dando", Jornal dos Sports, ano LV, núm. 17368, Rio de Janeiro, 3 de outubro de 1985 , p. 3 .

25 "Garimpeiros incendeiam quartel e expulsam PM de Serra Pelada", Jornal do Brasil, ano XCVI, núm. 188, Rio de Janeiro,13 de outubro de 1986, p. 6.

26 "Cooperativa Atribui a Inconformados", Jornal do Brasil, ano xcvi, núm. 190, Rio de Janeiro, 15 de outubro de 1986, p. 17.

27 "Garimpeiros querem a volta da PM à Serra", Diário do Pará, ano III, núm. 1209 X, Belém, 14 de outubro de 1986, p. 16.

${ }_{28}$ "PF é inculpada por conflito ocorrido em Serra Pelada", Jornal do Comércio, ano 160, núm. 12, Rio de Janeiro, 14 de outubro de 1986, p. 10.

29 "Garimpeiros incendeiam quartel e expulsam PM de Serra Pelada", Jornal do Brasil, ano XCVI, núm. 188, Rio de Janeiro, 13 de outubro de 1986, p. 6. 
riedades cometidas pela Polícia Militar, e com a Coogar, acusada de cometer várias irregularidades. ${ }^{30}$

\section{O EMBATE DOS PODERES: PROTESTO DOS GARIMPEIROS E VIOLÊNCIA GOVERNAMENTAL}

Em 1987, os garimpeiros conseguiram uma prorrogação temporária, o garimpo deveria ser encerrado em junho, mas o prazo foi estendido até o dia 31 de dezembro, data que poderia ser outra vez alterada, caso fosse comprovada que a exploração manual ainda seria segura. ${ }^{31}$ Ao se aproximar o final do ano, nas primeiras horas do dia 28 de dezembro, milhares garimpeiros ocuparam a ponte sobre o Tocantins, visando conquistar garantias para a manutenção do garimpo e o pagamento do dinheiro devido à Coogar pelo paládio coletado entre o ouro. ${ }^{32}$ A estrada de ferro da CVRD também ficou interditada (Ferreira, 2019).

Apesar do diálogo com representantes da Prefeitura de Marabá e do Governo do Estado ter sido iniciado no mesmo dia, os garimpeiros afirmaram que o desbloqueio da ponte só ocorreria caso suas exigências fossem acatadas. ${ }^{33}$ As polícias Federal e Militar se dirigiram ao local para observar a situação na área, sem, entretanto, intervir nesse primeiro momento.

Um pacto teria sido iniciado pelo qual seria garantido o rebaixamento emergencial dos taludes com a contratação de uma empresa chamada Construmil. Essa medida garantiria o funcionamento do garimpo durante 20 dias, até que fosse realizada uma licitação que promoveria o rebaixamento definitivo (Ferreira, 2019). No pacto também estava incluso a realização de investimentos para melhorar a qualidade de vida e moradia em Serra Pelada. Entretanto, tal acordo acabou não sendo aceito pelos garimpeiros, visto que no mesmo não estaria garantida a liberação definitiva para que a extração do ouro continuasse pela garimpagem, o que provocou desconfiança entre os ga-

30 "Garimpeiros só negociam com Jader", Jornal do Brasil, ano xcvi, núm. 189, Rio de Janeiro, 14 de outubro de 1986, p. 12.

31 "Prorrogado o prazo de garimpagem em Serra Pelada", Diário do Pará, ano IV, núm. 1378, Belém, 26 de abril de 1987, p. 8.

${ }_{32}$ "Garimpeiros de Serra Pelada fecham a Ferrovia de Carajás", Jornal do Brasil, ano xcVII, núm. 264, Rio de Janeiro, 29 de dezembro de 1987, p. 4.

33 “Garimpeiros param Marabá”, Diário do Pará, ano v, núm. 1623, Belém, 29 de dezembro de 1987, p. 1. 
rimpeiros, que acharam que aquela era apenas mais uma tentativa de ganhar tempo para depois tentarem proibir a lavra manual (Ferreira, 2019).

Novas propostas foram feitas no dia seguinte, mas as lideranças dos garimpeiros ao deixar a sede da Prefeitura de Marabá ouviram que ordens já haviam sido dadas para o desbloqueio da ponte (Ferreira, 2019). A repressão violenta da polícia ocorreu na tarde do dia 29 de dezembro, aproximadamente às $19 \mathrm{~h} .{ }^{34}$ Hélio Gueiros autorizou o desbloqueio da ponte ocupada como uma forma de "demonstração de força" contra os garimpeiros manifestantes ${ }^{35}$ que não aceitaram a negociação para a suspensão do bloqueio. ${ }^{36} \mathrm{Com}$ isso, uma tropa de 340 policiais atirou contra os manifestantes, atacando-os e perseguindo-os durante quinze minutos (Ferreira, 2019). Um grupo de 300 policiais teria começado o ataque pelo lado de Marabá, enquanto os demais 40 membros da tropa teriam cercado os garimpeiros pelo lado oposto da ponte, que se interliga com o município de São Félix (Ferreira, 2019).

Em depoimento, o governador criticou as ações da Polícia Federal no garimpo, que estariam extrapolando de suas atribuições, e ainda a Nelson Marabuto, um dos integrantes do Grupo de Trabalho criado pelo Congresso para discutir sobre os problemas de Serra Pelada, por fazer promessas inviáveis aos garimpeiros. ${ }^{37}$ É possível que a ação autorizada por Gueiros não fosse demonstração de força apenas aos garimpeiros, mas também à Policia Federal, à Marabuto e ao governo central, à fim de mostrar seu poder sobre o território (Ferreira, 2019). O Jornal do Brasil de 31 de dezembro de 1987 menciona que cerca 200 soldados da Polícia Militar atacaram os manifestantes.

As primeiras notícias sobre as vítimas da repressão policial falavam de duas mortes: Maria Valdenora de Souza, que estava grávida, e um rapaz conhecido como Careca, juntamente com onze feridos; $;^{38}$ a quantidade de vítimas variava a cada matéria de jornal, mas os números admitidos pela polícia e pelo governo do estado eram inferiores ao número de desaparecidos estimado

34 "PM mata cinco garimpeiros e libera a ferrovia no Pará", Jornal do Brasil, ano XCVII, núm. 265, Rio de Janeiro, 30 de dezembro de 1987, p. 4.

35 "Hélio: Demonstração de Força para Desestimular Garimpeiro", Diário do Pará, ano v, núm. 1625, Belém, 31 de dezembro de 1987, p. 12.

36 "PM do Pará intervém junto a garimpeiros", Jornal do Comércio, ano Lxxxiv, núm. Últimas Notícias, Manaus, 30 de dezembro de 1987, p. 12.

37 "PM pode ter massacrado 100 garimpeiros em Marabá", Jornal do Brasil, Rio de Janeiro, ano XCVII, núm. 267, 2 de janeiro de 1988, p. 5.

38 "Tumulto na desobstrução da Ponte do Tocantins em Marabá", Diário do Pará, ano v, núm. 1624, Belém, 30 de dezembro de 1987, p. 12. 
pelos garimpeiros. Uma das versões narradas diz que os soldados avançaram por um lado da ponte, deixando uma lateral livre para a saída dos garimpeiros, a ação seguia tranquila até um garimpeiro ter atingido um dos policiais com uma pedra, tiros para o alto teriam sido usados como advertência, não obstante, os garimpeiros teriam sido insuflados a resistirem, utilizando armas se fosse preciso, com isso a polícia disparou contra os manifestantes. ${ }^{39}$ Em outra versão, a polícia teria chegado já atirando, no momento em que vários garimpeiros estavam em fila, para receber rações.

Os policiais teriam assassinado primeiro um casal de garimpeiros na estação de passageiros da empresa Transbrasiliana e depois seguido para a ponte sobre o rio Tocantins, onde além de usarem armas de fogo, também agrediram os garimpeiros com cassetetes, chutes e socos. Durante o ocorrido, algumas pessoas teriam sido pisoteadas, e outras pularam da ponte, se jogando no rio Tocantins para tentar escapar. ${ }^{40}$

Além de atacar os garimpeiros que estavam bloqueando a ponte em Marabá, os policiais teriam impedido à força um grupo que se encontrava em Parauapebas e que se dirigia para o bloqueio em Marabá. ${ }^{41}$ Estima-se que 25 pessoas saíram feridas desse confronto com a polícia. Segundo os garimpeiros, o grupo seguia pacificamente em direção à Marabá, quando foram surpreendidos pelos policiais, além da violência sofrida, os garimpeiros teriam sido saqueados durante o conflito.

A violência deflagrada pela Polícia Militar sob as ordens de Hélio Gueiros, também foi alvo de crítica da Polícia Federal. Os agentes federais se posicionaram a favor das denúncias dos garimpeiros de que houve mais mortes do que as oficialmente declaradas, e de que os corpos de outros garimpeiros que teriam morrido durante o conflito foram recolhidos e escondidos pela Polícia Militar. ${ }^{42}$ As denúncias de ocultação dos cadáveres relatavam que um ônibus da empresa Transbrasiliana teria sido usado para esconder e transportar os corpos, assim como uma Kombi policial, que teria desaparecido com quatro

39 "Tumulto na desobstrução da Ponte do Tocantins em Marabá”, Diário do Pará, ano v, núm. 1624, Belém, 30 de dezembro de 1987, p. 12.

40 "PM mata cinco garimpeiros e libera a ferrovia no Pará", Jornal do Brasil, ano xCVII, núm. 265, Rio de Janeiro, 30 de dezembro de 1987, p. 4.

41 "PM mata cinco garimpeiros e libera a ferrovia no Pará", Jornal do Brasil, ano XCVII, núm. 265, Rio de Janeiro, 30 de dezembro de 1987, p. 4.

42 "Delegado federal acusa PM de brutalidade na ação de Marabá", Jornal do Brasil, ano XCVII, núm. 266, Rio de Janeiro, 31 de dezembro de 1987, p. 4. 
cadáveres, cogitava-se ainda que um sepultamento clandestino realizado no cemitério de Marabá poderia ser de um garimpeiro gravemente ferido, que foi retirado do hospital por guardas da Polícia Militar ${ }^{43}$ (Ferreira, 2019). A ação investigativa da Polícia Federal sobre o massacre, não obstante cessou, alguns dias depois. ${ }^{44} \mathrm{O}$ massacre e o governador do Pará também foram criticados por outros políticos, partidos e entidades brasileiros que tentaram responsabilizar Gueiros judicialmente. ${ }^{45}$

As declarações feitas pelos garimpeiros descrevem atos de violência indevida e extremada. Alegava-se que uma mulher grávida de sete ou oito meses teria sido jogada da ponte por soldados da PM; que um garoto de seis ou sete também teria sido lançado da ponte; que um garimpeiro teria sido sequestrado pela PM, ao ser colocado dentro de um Fusca; além da morte de garimpeiros fora da área da ponte do rio Tocantins, o que sugere que a PM teria perseguido os garimpeiros. ${ }^{46}$

A matéria no volume especial de O Estado de São Paulo, de 19 de dezembro de 2010, declara que além da Polícia Militar, o Exército também teria participado do massacre, oferecendo apoio e logística. Segundo testemunha, o Exército teria ficado acampado do lado direito de quem sai de Nova Marabá, enquanto a Polícia Militar do lado esquerdo, em São Félix. Os policiais teriam cercado os dois lados da ponte e atacado primeiro com gás de pimenta e depois avançaram sobre os protestantes, atirando com metralhadoras e fuzis calibre $.765 .{ }^{47} \mathrm{~A}$ repressão teria aparentemente se prolongado dias após o ataque, visto que os garimpeiros acreditam que uma das testemunhas teria sido morta a pauladas por um grupo desconhecido, após ter dado entrevista à TV Liberal afirmando que teria visto oito cadáveres. ${ }^{48}$

${ }_{43}$ "PM massacrou garimpeiros, afirma relatório feito pela Polícia Federal”, Folha de São Paulo, ano 68, núm. 10104, São Paulo, 6 de janeiro de 1988, p. 12.

44 "Governo manda aprofundar as cavas de Serra Pelada", Jornal do Brasil, ano xcviI, núm. 273, Rio de Janeiro, 8 de janeiro de1988, p. 4.

45 "Massacre", Correio de Notícias, ano vil, núm. 1976, Curitiba, 8 de janeiro de 1988, p. 3; "Pт quer CPI para apurar o que aconteceu em Marabá", Jornal do Brasil, ano XCVII, núm. 280, Rio de Janeiro, 15 de janeiro de 1988, p. 5.

46 "Para garimpeiros, há mais mortos", Diário do Pará, ano v, núm. 1625, Belém, 31 de dezembro de 1987 , p. 8.

47 "Guerra de São Bonifácio. Guerras desconhecidas do Brasil", O Estado de São Paulo, ano 0, núm. 0, p. 20, São Paulo, 19 de dezembro de 2010.

48 "Guerra de São Bonifácio. Guerras desconhecidas do Brasil", O Estado de São Paulo, ano 0, núm. 0, p. 20, São Paulo, 19 de dezembro de 2010. 
Dez dias após o ocorrido, contrariando a previsão dos garimpeiros, os corpos dos garimpeiros que teriam se jogado ou sido lançados no rio Tocantins pelos policiais, ainda não tinham aparecido, ${ }^{49}$ mas os garimpeiros estimavam que 133 pessoas ainda estavam desaparecidas. ${ }^{50}$ Mesmo após um laudo investigativo da polícia federal denunciando a brutalidade do ocorrido, prevaleceu a impunidade.

Ainda que o governador Hélio Gueiros tenha lamentado os "danos fatais" ocorridos na repressão aos manifestantes, ${ }^{51}$ seu discurso e o da polícia ${ }^{52}$ evidenciam que o uso da força era necessário para que o governo não fosse desmoralizado. A perda de autoridade é uma das condições propícias para o uso da violência (Arendt, 1994), e o estado se favoreceu da condição de monopólio do uso legítimo da força que possui na aplicação da ordem (Weber, 1999), como justificativa de seu ato repressivo e agressivo. Hélio Gueiros alegou que tinha se comprometido em atender as reivindicações dos garimpeiros, mas que estes insistiram no bloqueio da ponte, não acreditando em sua palavra, e atrapalhando a ordem local, pois estariam ocorrendo saques em caminhões com produtos alimentícios, e o bloqueio estava impossibilitando a circulação na ponte, o que supostamente estaria preocupando a população de Marabá. ${ }^{53}$

O massacre na ponte não representou o fim do garimpo de Serra Pelada, que foi oficialmente fechado em 1992, nem igualmente representou o último ato de violência que os garimpeiros tiveram que enfrentar. Em 2014, outro conflito entre garimpeiros e a Polícia Militar aconteceu. Em reportagem televisiva no Câmera Record aparecem imagens de um protesto com 7000 garimpeiros, com idade média de 65 anos. Na reação da polícia, tiros e bombas foram disparados, pelas imagens vemos garimpeiros feridos na perna, mão, braço e pés. $O$ ataque continuou, mesmo com feridos no chão e com o recuo dos manifestantes. Nesse caso, computaram-se 25 feridos.

49 "Passados 10 dias, corpos não aparecem", Jornal do Brasil, ano XCVII, Rio de Janeiro, 7 de janeiro de 1988 , p. 5.

50 "Delegado federal diz que PM matou 20 em Marabá", Jornal do Brasil, ano xcvir, núm. 266, Rio de Janeiro, 7 de janeiro de 1988, p. 5.

51 "Hélio: Demonstração de Força para Desestimular Garimpeiro", Diário do Pará, ano v, núm. 1625, Belém, 31 de dezembro de 1987, p. 12.

52 "Comando da PM diz que tropa só revidou ataques", Diário do Pará, ano v, n. 1625, Belém, 31 de dezembro de 1987, p. 8.

53 "Hélio: Demonstração de Força para Desestimular Garimpeiro", Diário do Pará, ano v, n. 1625, Belém, 31 de dezembro de 1987, p. 12. 


\section{DISCUSSÃO}

O caso de Serra Pelada exemplifica as questões de disputa de poder entre sociedade e estado e tentativa de controle dos corpos pelo poder governamental. Serra Pelada ganhou destaque na história devido ao grande número de garimpeiros que se concentraram em um espaço em busca do sonho do bamburro. Para evitar conflitos na região, o governo militar implantou várias medidas para exercer seu poder sobre os garimpeiros, proibindo o uso de armas na vila, consumo de bebidas alcóolicas e a presença de mulheres, e durante um tempo, a entrada de novos garimpeiros. Entretanto, esse controle estava restrito à corrutela, sendo permitido aos garimpeiros circular por outras cidades.

Há, portanto, uma distinção entre o espaço dentro e fora do garimpo. A tentativa de aplicação de uma disciplina estava limitada ao espaço do garimpo, visto que o governo militar não exercia o mesmo controle social e econômico na vida dos garimpeiros nas cidades e vilas que já existiam e foram surgindo em torno do garimpo. Além de que, como mencionado ao longo deste artigo, as tentativas de disciplinalização não impediram que as pessoas procurassem meios de descumprir as regras impostas, os corpos, portanto, não eram tão dóceis.

Nessa busca desenfreada pelo ouro, outro destaque produzido foi a grande cava, que virou posteriormente argumento de segurança para a finalização da lavra manual, e, portanto, de disputa de poder. Enquanto os garimpeiros protestavam por seus direitos de permanecerem a explorar o ouro, por já terem, inclusive, movido uma montanha nas costas, e ajudarem a sanar a dívida externa, algumas entidades governamentais, como a Companhia Vale do Rio Doce e o DNPM, apontavam o baixo aproveitamento da lavra manual e os riscos de acidentes devido ao desabamento dos taludes.

As disputas de poder continuaram durante todo o funcionamento do garimpo com o poder governamental tentando ditar sobre o período em que o garimpo estaria aberto ou fechado para a lavra, sobre as áreas de catas que deveriam ser interditadas ou proibidas de serem garimpadas até segunda or$\mathrm{dem}$. Enquanto os garimpeiros insatisfeitos com as tentativas de fechamento e controle da extração de ouro se uniam em protestos, reafirmando seu poder enquanto grupo, e, portanto, grande contingente que poderia causar reacender os conflitos históricos na área.

Se até 1987, as disputas entre garimpeiros e o governo foram resolvidas sem grande violência, o Massacre de São Bonifácio, contrariamente, foi uma 
resolução sangrenta que não concedeu aos protestos dos garimpeiros, mas não garantiu também os desejos das entidades que desejavam a lavra manual. Arendt (1994) afirma que poder e violência são termos opostos, pois a violência é acionada devido a desintegração, ou no caso do Massacre da Ponte, do receio da desintegração do poder. Esse aspecto ficou evidenciado no massacre contra os garimpeiros durante a fala de Hélio Gueiros, que justificou tal ato como uma medida para que seu governo não ficasse desmoralizado. A violência utilizada foi, assim, mais uma das formas que as autoridades governamentais utilizaram para tentar controlar os garimpeiros.

\section{CONCLUSÃO}

A descoberta de ouro em Serra Pelada atraiu um grande contingente de pessoas para a região de Carajás. Além do atrativo causado pelo ouro, o contexto vivido nas redondezas do novo garimpo e no restante do Brasil favoreceram o deslocamento populacional. A concentração de pessoas se tornou logo um problema que precisava ser controlado para evitar conflitos agrários e outros empecilhos para o projeto de mineração em Carajás. Para resolver esse problema, o governo militar assumiu o controle administrativo de Serra Pelada, deixando no comando o Major Sebastião Curió. Controlar o espaço interno do garimpo era controlar a extração do ouro, cujo único comprador legalizado, a Caixa Econômica Federal, instalou um posto em Serra Pelada.

Se manter o garimpo aberto, em um primeiro momento, fora vantajoso para garantir que aquelas milhares de pessoas que para lá se deslocaram se mantivessem ocupadas em atividade que estava rendendo várias toneladas de ouro, posteriormente, o governo vislumbrou outro benefício para o garimpo de Serra Pelada: milhares de eleitores. O número de garimpeiros se tornou, assim, um tipo de poder, que, ao mesmo tempo, poderia ameaçar a ordem que o governo queria manter, ou garantir essa ordem, ao eleger, candidatos de interesse governamental. Com grandes vantagens e temerosas desvantagens, a lavra manual prosseguiu em Serra Pelada, à despeito das críticas realizadas pelos técnicos do DNPM. Se a extração mecanizada era supostamente a técnica mais eficaz, a tecnologia da garimpagem era, naquele momento, a mais "poderosa".

Nesse jogo de poderes, a mineração só sairia definitivamente vencedora no ano de 1992, até essa data, o embate prosseguiu entre os garimpeiros que 
reivindicavam por seu direito de explorar o ouro. Até 1987, os garimpeiros conseguiram se beneficiar do seu número como poder de barganha para alcançar seus objetivos, ainda que os ganhos fossem parciais. Entretanto, nesse ano, o governador Hélio Gueiros menosprezou o poder numérico dos garimpeiros que protestavam, valendo-se da violência como afirmação de autoridade e poder, O Massacre da Ponte de 1987, não foi um conflito para encerrar o garimpo, mas sim decorrente de uma afirmação de quem detinha a autoridade para determinar a continuação ou término da manifestação. Nesse embate, mais uma vez foi utilizado o discurso de necessidade de controle da segurança para justificar as ações tomadas. Segurança para o estado ameaçado pelo bloqueio da ponte sobre o rio Tocantins, e, principalmente, segurança para o governo que deveria manter sua autoridade e poder.

\section{LISTA DE REFERENCIAS}

Almeida, A. W. (2008). Antropologia dos Archivos da Amazônia. Rio de Janeiro: Casa 8/ Fundação Universidade do Amazonas.

Almeida, J. J. (2011). Os riscos naturais e a História: o caso das enchentes em Marabá (PA). Revista Tempos Históricos, 15(2), 205-238. Recuperado de http://e-revista. unioeste.br/index.php/temposhistoricos/article/view/7205

Araújo, J. M. L. (2015). A Amazônia e o Nordeste no discurso governamental: Trabalhadores rurais em deslocamento (1970-1985). (Tesis de maestria inédita). Programa de Pós-Graduação em História, Universidade Federal de Pernambuco, Recife.

Arendt, H. (1994). Sobre a violência. (Trad. André Duarte). Rio de Janeiro: Relume Dumará.

Barbosa, L. (1981). Garimpo e meio ambiente: águas sagradas e águas profanas. Estudos Históricos, 4(8), 229-243.

Cleary, D. (1992). A garimpagem na Amazônia: uma abordagem antropológica. Edição Brasileira: UFRJ.

Ferreira, P. R. (2019). Encurralados na ponte: o massacre dos garimpeiros de Serra Pelada. Belém: Paka-Tatu.

Figueiredo, B. R. (1984). Garimpo e a mineração no Brasil. Em G. A. Rocha (coord.), Em busca do ouro: garimpos e garimpeiros no Brasil (pp. 35-86). São Paulo: Editora Marco Zero.

Foucault, M. (1987). Vigiar e punir: nascimento da prisão. (Trad. de Raquel Ramalhete). Petrópolis: Vozes. 
Foucault, M. (2008). Segurança, território, população. São Paulo: Martins Fontes.

Freyre, G. (2003). Casa Grande \& Senzala: formação da família brasileira sob o regime da economia brasileira. (Apresentação de Henrique Cardoso). São Paulo: Global.

Goffman, E. (1987). Manicômios, prisões e conventos (2a ed.). São Paulo: Perspectiva.

Hobbes, T. (1983). Leviatã. Matéria, forma e poder de um Estado eclesiástico e civil. (Trad. de João Paulo Monteiro e Maria Beatriz Nizza da Silva) (3a ed., Coleção Os Pensadores). São Paulo: Abril Cultural.

Kostcho, R. (1984). Serra Pelada: uma ferida aberta na Selva. São Paulo: Editora Brasiliense.

Mathis, A. (1995). Serra Pelada. Papers do NAEA, 50, 3-19.

Mathis, A. (1997). Serra Pelada. Em M. C. Coelho y R. G. Costa (coords.), Dez anos da Estrada de Ferro Carajás (pp. 275-293). Belém: NAEA.

Mathis, A., Brito, D. C., Brüseke, F. J. (1997). Riqueza volátil: a mineração de ouro na Amazônia. Belém: Cejup.

Monteiro, M., Coelho, M., Cota, R., Barbosa, E. (2010). Ouro, empresas e garimpeiros na Amazônia: o caso emblemático de Serra Pelada. Revista Pós Ciências Sociais, 7(13). Recuperado de http://www.periodicoseletronicos.ufma.br/index.php/ rpcsoc/article/view/176

Salomão, E. (1984). A condição e o ofício de garimpar. Em G. A. Rocha (coord.), Em busca do ouro: garimpos e garimpeiros no Brasil (pp. 35-86). São Paulo: Editora Marco Zero.

Santos, B. S. (2010). Descolonizar el saber, Reinventar el poder. Montevideo: Trilce-Extensión Universitaria-Universidad de la República.

Schwarcz, L. (1993). O espetáculo das raças: cientistas, instituições e questão racial no Brasil, 1870-1930. São Paulo: Companhia das Letras.

Weber, M. (1999). Conceitos sociológicos fundamentais. Em Economia e sociedade: fundamentos da sociologia compreensiva (vol. 1, pp. 5-39). (Trad. de Regis Barbosa e Karen Elsabe Barbosa). Brasília, DF: Editora Universidade de Brasília/São Paulo: Imprensa Oficial do Estado de São Paulo.

\section{OUTRAS FONTES}

\section{Jornais}

Alto Madeira.

Correio de Notícias. 
Diário da Tarde.

Diário do Pará.

Folha de São Paulo.

Jornal do Brasil.

Jornal do Comércio.

Jornal dos Sports.

Luta Democrática.

Movimento.

O Estado de São Paulo.

Última Hora. 